\title{
HORTO D'EL REY DE OLINDA, PERNAMBUCO: HISTÓRIA, ESTADO ATUAL E POTENCIALIDADES DA COBERTURA VEGETAL DE UMA ÁREA VERDE URBANA (QUASE) ESQUECIDA
}

\author{
Isabelle Maria Jacqueline Meunier ${ }^{(1)}$, Horivani Conceição Gomes da Silva ${ }^{(2)}$
}

(recebido em 19.02.2009 e aceito para publicação em 21.05.2009)

\begin{abstract}
RESUMO
Horto d'El Rey é a denominação de uma área verde situada no Centro Histórico de Olinda, Pernambuco, onde no século XIX funcionou um horto de aclimatação, produção e distribuição de mudas. A análise realizada neste trabalho identificou aspectos históricos e ambientais determinantes ou restritivos de usos da área, na perspectiva de criação de um parque urbano. O Horto d'El Rey passou por fases distintas, iniciando-se por período dedicado ao estudo da flora nativa e exótica, assumindo, em seguida, importante papel de entreposto de mudas para, por fim, servir ao cultivo e estudo de plantas medicinais, já na fase de decadência com a qual se encerrou seu funcionamento em 1842. Sob domínio privado, foi manejado como um extenso quintal. A vegetação arbórea, com baixa diversidade, é dominada por Spondias mombin, Mangifera indica e Elaeis guinnensis, e apresenta importância na amenização climática, abrigo e alimentação da fauna e proteção ao relevo. O grande porte das árvores, a extensa cobertura de copas e o relevo local são atributos paisagísticos importantes. Aponta-se a necessidade de estabelecer o uso público da área como parque urbano, adotando-se limitações de acesso, incentivo às práticas de lazer contemplativo e às atividades educativas e de informações históricas e culturais.

Palavras chave: Área verde; Horto d'Del Rey; jardim botânico de Olinda; Olinda.
\end{abstract}

${ }^{1}$ Engenheira florestal M.Sc., professora adjunta do Departamento de Ciência Florestal, UFRPE, Av. D. Manuel de Medeiros, s/n Dois Irmãos, Recife, PE. E-mail: imjmeunier@gmail.com ${ }^{2}$ Engenheira florestal graduada pela UFRPE. E-mail: horivani@hotmail.com 
Horto D'el Rei de Olinda, Pernambuco...

OLINDA'S “HORTO D'EL REY”: HISTORY, STATUS OF CONSERVATION AND

VEGETATION'S POTENTIAL OF ONE URBAN GREEN AREA (ALMOST)

FORGOTTEN

\begin{abstract}
"Horto d'El Rey" is the name of a green area located in the Historic Center of Olinda, Pernambuco, where there was, in the nineteenth century, a garden of acclimatization, production and distribution of seedlings. This study identified historical and environmental factors, determinants or restrictive for the use of the area, in view of creating an urban park. The Horto d'El Rey had different phases, starting by a period devoted to the study of native and exotic flora. Later, it took an important role on storage and distribution of seedlings. Next, it served for the cultivation and study of medicinal plants, until be closed in 1842. Under the private domain, was managed as an extensive garden. The vegetation, with low plant diversity, is dominated by Spondias mombin, Mangifera indica and Elaeis guinnensis and presents important in alleviating climate, shelter and food for wildlife and protection to the relief. The large trees, the extensive coverage and the relief are important landscape attributes. It is necessary to establish the public use the area as urban park, are adopting restrictions on access, encouraging the practice of contemplative leisure and educational activities and cultural and historical information.
\end{abstract}

Key words: Green area; Horto d'Del Rey; Olinda's botanic garden; Olinda. 


\section{INTRODUÇÃO}

O Horto d'El Rey, em Olinda, Pernambuco, também conhecido como o "antigo Jardim Botânico de Olinda", foi oficialmente estabelecido em 1811, com o título de Real Viveiro de Plantas de Olinda, sob a inspiração do grande naturalista Manuel Arruda da Câmara e atendendo uma determinação real. Após algumas décadas de funcionamento, tornou-se uma propriedade particular, constituindo-se hoje em uma área verde urbana importante e demandando urgentes medidas para a sua conservação.

Em 2008, foi apresentada uma proposta de implementação e gestão da qual fez parte uma análise da cobertura vegetal, com foco na caracterização florística e ecológica e nas suas potencialidades e restrições para uso público. Este trabalho constitui a ampliação dessa análise, integrante do relatório final (PICCHIONE, 2008) e pretende, acima de tudo, dar maior conhecimento às pessoas de parte da história de Pernambuco e apontar algumas alternativas para o futuro dessa área verde no Centro Histórico de Olinda, Patrimônio Histórico e Cultural da Humanidade ${ }^{1}$, com vistas a subsidiar futuros projetos de implantação e manejo de um parque urbano.

\section{MATERIAIS E MÉTODOS}

Área de estudo: O Horto D’El Rey localiza-se em Olinda, Pernambuco, no seu sítio histórico, abrangendo cerca de 14 ha que se estendem da encosta da Sé até o vale do Bonsucesso, limitando-se com o turístico Alto da Sé e os bairros do Carmo, Amaro Branco, Amparo e Bonsucesso, reunindo lotes de diferentes proprietários.

Com clima tropical úmido, situado no domínio da Mata Atlântica, em área de prováveis matas de restinga, há muito suprimidas, o local apresenta topografia acidentada, com declividades de mais de 30\% e áreas inundáveis no fundo do vale. De acordo com o Plano Diretor de Olinda, trata-se de uma Zona de Proteção Ambiental Recreativa (ZPAR 04), tendo o Decreto Municipal 072/2005 declarado a área como uma ARIE - Área de Relevante Interesse Ecológico.

Métodos: Foram realizadas pesquisas bibliográficas e consultados registros históricos relativos à área, disponíveis em acervos do Instituto Histórico e Arqueológico de Pernambuco e da Fundação Joaquim Nabuco. Foi feita a identificação das plantas a partir do reconhecimento em visitas à área e de coleta de material botânico fértil, com posterior comparação com exsicatas do Herbário Sérgio Tavares, do Departamento de Ciência Florestal da Universidade Federal Rural de Pernambuco. As avaliações e

\footnotetext{
${ }^{1}$ O Centro Histórico de Olinda foi reconhecido pela UNESCO como Patrimônio Histórico e Cultural da Humanidade em 1982 e, no mesmo ano, Olinda recebeu o título de Cidade Ecológica por Decreto Municipal $N^{\circ} 23$, de 29 de junho.
} 
Horto D'el Rei de Olinda, Pernambuco...

sugestões foram resultados das análises de campo e discussões, à luz da bibliografia técnica especializada e da legislação pertinente. 


\section{RESULTADOS E DISCUSSÕES}

\section{Síntese histórica}

O local hoje conhecido como Horto d'El Rey tem sua história associada à criação de um jardim botânico em Pernambuco, concebido de acordo com as necessidades da época (final do século XVIII e início do século XIX).

Segundo Souza (1976) ${ }^{2}$ apud Rocha \& Cavalheiro (2001), os mais antigos jardins botânicos do mundo se estabeleceram na Mesopotâmia, no Egito antigo e na América pré-colombiana, não precisando a localização e a época em que isso se deu. Na Mesopotâmia, imagina-se que o autor se refira aos jardins de Nabucodonossor, voltado ao cultivo de plantas para a apreciação estética de reis e nobres. Já na Grécia, relata-se a existência de jardim botânico próximo a Atenas, criado por Teofrasto (372 287 a.C.), considerado o "pai da Botânica", tendo como objetivo manter coleções de plantas para estudos e ensino (ROCHA \& CAVALHEIRO, 2001)

Só no Renascimento europeu volta-se a se encontrar referências aos jardins botânicos ocidentais. Na Idade Moderna, a Europa foi pródiga na criação de jardins botânicos voltados principalmente ao estudo da flora e à aclimatação e ao cultivo de plantas úteis, em grande parte originária das novas colônias que foram se somando ao poderio das grandes nações européias. Assim, foram criados os jardins botânicos de Pisa (1543), Pádua (1545), Montpellier e Heidelberg (1593), Oxford (1621), Paris (1635), Berlim (1646) e Upsala (Suécia, em 1655). Nesse último, destaca-se a atuação de Carl von Linneus (1707-1772), considerado o "pai da Taxonomia", criador do "sistema de classificação binária" dos seres vivos.

Os jardins botânicos foram estabelecidos não só nas cidades européias, mas também nas novas colônias de França, Inglaterra e Holanda (BEDIAGA, 2007). Conforme relata Silva (2004), deu-se em Recife, no século XVII, a instalação do primeiro jardim botânico em colônia americana, durante a ocupação holandesa, mais precisamente durante o governo do conde João Maurício de Nassau (1637 - 1644), reunindo espécimes da flora coletadas durante as expedições aos novos domínios dos flamencos. O interesse que a flora local despertou nos dominadores holandeses é comprovado, por exemplo, pela organização de um herbário (Herbarium vivum brasilienses) por Georg Marggraf durante sua estada em Pernambuco (MOULIN et al., 1986). Juntamente a Marggraf (nota-se também Marcgrave), Guilherme Piso, outro grande naturalista nassoviano, médico particular do Conde Maurício de Nassau, dedicou-se aos estudos das plantas medicinais nativas.

\footnotetext{
${ }^{2}$ SOUSA, H.M. Os jardins botânicos. Suplemento Agrícola do Estado de São Paulo, n. 1084 p.7, 1976.
} 
Horto D'el Rei de Olinda, Pernambuco...

Após a expulsão dos holandeses e a destruição total do jardim de Nassau, até o final do século XVIII, não houve outra iniciativa de instalação de jardim botânico em Pernambuco, necessidade que veio a ser ressaltada por Manuel Arruda da Câmara no seu Discurso sobre a Utilidade da Instituição de Jardins nas Principais Províncias do Brasil (MELLO, 1982) e já nessa época reconhecida pelo Aviso Régio de 1798, no qual se relevava a importância de criação dessas instituições em Pernambuco, Bahia, Minas Gerais e São Paulo, a exemplo do que havia sido criado em Belém em 1796.

Desde 1768, Portugal mantinha o Jardim Botânico de Ajuda que, juntamente à reforma da Universidade de Coimbra (1772), constituiu-se em marco da política ilustrada do Marques do Pombal, primeiro-ministro do rei português D. José. Juntamente aos jardins botânicos de Caiena, Belém e Rio de Janeiro, o Horto de Olinda viria a integrar a "rede luso-brasileira de jardins", conforme Sanjad (2003) apud Beidaga (2007).

O Discurso sobre a Utilidade da Instituição de Jardins nas Principais Províncias do Brasil é uma obra curiosa e importante para compreender a lógica colonialista e as preocupações da ciência da época (1810). Nesse documento, Arruda da Câmara alerta o Príncipe Regente para a utilidade dos "hortos ou jardins", tecendo longa argumentação sobre a importância dos recursos vegetais para o desenvolvimento do Brasil e sobre as oportunidades do país com extensão continental e grandes extensões de solos férteis, e exemplifica experiências de sucesso de introdução de espécies, como a do café nas Antilhas.

O autor também expõe o seu ponto de vista sobre as características do local próprio para abrigar esse jardim, fazendo crer que tinha em mente exatamente a área do atual Horto d'El Rey, onde já se davam aulas de botânica, por iniciativa do Seminário de Olinda, do qual é vizinho. Além de ter delineado o local, Arruda da Câmara já propunha, implicitamente, o Padre João Ribeiro como seu inspetor. Transcreve-se, a seguir, trecho do seu Discurso:

"Todavia, a escolha de lugar para a instituição destes Hortos não é coisa indiferente; pois que, havendo de transplantar-se neles vegetais de diversas partes do mundo e de diferentes naturezas, uns serão mais próprios de terras argilosas, outros areiscas; a um é proveitosa a exposição dos ventos, a outros o resguardo deles; uns vegetarão bem em lugares úmidos, outros nos secos, etc.

Cumpre, pois, que o lugar que se destine para o jardim, inclua várzea, mais ou menos fresca, terra argilosa, areísca, altos expostos ao vento e ao sol; e será ainda mais necessário que pelo jardim passe algum arroio ou fonte corrente, com o que se possam facilmente regar as plantas." 
Sobre o inspetor do jardim, recomenda Arruda da Câmara que "se escolha um Inspetor ativo, instruído em princípios de agricultura; e muito melhor será, se possuir a ciência da Botânica e souber desenhar, para descrever e desenhar as espécies novas e raras que se criarem no seu Horto." O Padre João Ribeiro era professor de desenho no Seminário de Olinda, discípulo de Botânica de Arruda da Câmara e, segundo o próprio mestre, no mesmo documento, tinha procurado introduzir em Pernambuco a cultura de algumas plantas úteis e exóticas, além de ter feito "curiosa e filosófica observação sobre um admirável fenômeno na maneira de frutificarem as mangabeiras" (MELLO, 1982).

Essa conjugação de interesses deu origem à implantação do jardim botânico de Olinda, com o nome de Real Viveiro de Plantas, em 1811, que parece ter cumprido seu papel por algumas poucas décadas. Os documentos da época mostram que a iniciativa tinha objetivo agrícola, científico e econômico; sua finalidade era ser um local onde fossem aclimatadas plantas úteis ao comércio de especiarias europeu e ainda onde se conservasse e ampliasse o conhecimento sobre a flora nativa.

O ofício do governador Caetano Pinto de Miranda Montenegro ao Conde Linhares, em 21 de junho de 1811 (FIDEM, 1979), esclarece que em maio de 1811 chegou ao porto do Recife a primeira remessa de plantas e sementes de especiarias, vindas de Caiena, sendo parte destinada ao plantio no local, trazidas por Mr. Estevan Paulo Germain, também originário de Caiena, considerado pelo governador como experiente "na cultura e benefício das especiarias", mas de caráter "alguma coisa volúvel". Nessa época, o Padre João Ribeiro Pessoa Montenegro era o encarregado do viveiro de plantas e considerado por Caetano Pinto como "eclesiástico de muita probidade de bastantes luzes em história natural".

Estevan Germain assumiu a direção do Real Viveiros de Plantas em 1812 recebendo do padre João Ribeiro, segundo FIDEM (1979), uma relação de plantas encontradas aclimatadas no jardim, entre as quais se encontravam 300 girofleiros (cravo-da-Índia, Sygygium caryophillus, Myrtaceae, especiaria das mais procuradas e com múltiplos usos), 10 árvores-do-pão (fruta-pão, Artocarpus altilis, Moraceae, provavelmente introduzido em Pernambuco nessa época, proveniente de Caiena), 17 caneleiras (Cinnamomum zeylanicum, Lauraceae), carambola e bilimbi (Averrhoa carambola e A. bilimbi, esses também provavelmente cultivados pela primeira vez em Pernambuco no Jardim Botânico de Olinda), entre outras espécies consideradas com potencial econômico. Mr. Germain manteve-se na direção até 1817, apesar de ser descrito por Tollenare, nesse mesmo ano, como não tendo "o mais ligeiro conhecimento de botânica". 
Horto D'el Rei de Olinda, Pernambuco...

Se antes mesmo da sua criação oficial, o local tinha servido às observações e experimentações botânicas do padre João Ribeiro e do próprio Arruda da Câmara, de 1812 em diante, o Real Viveiro foi levado à condição de entreposto e distribuidor de sementes e mudas, vindas principalmente do Jardim Botânico do Grão-Pará, em Belém. Em 1818, recebeu o nome de Jardim de Especiarias e Plantas Exóticas, o que traduz muito bem seus objetivos.

Depoimentos de visitantes do século XIX, como o comerciante francês Tonellare $^{3}$ e o naturalista escocês George Gardner ${ }^{4}$, depois diretor do Jardim Botânico do Ceilão, mencionam as espécies exóticas cultivadas no local e não apresentam comentários ressaltando a presença de espécies nativas. Até a Hancornia speciosa (mangabeira) que, segundo Freyre (1939), encantou Gardner, parece ter sido provada, segundo o cronista, "além do horto" (FREYRE, 1939). Essa mesma mangabeira é mencionada por Arruda da Câmara como cultivada nos arredores de Olinda em meados de 1810, tendo o botânico a descrito com o nome de Ribeirea sorbilis, em homenagem ao Padre João Ribeiro.

Nessa época, as exóticas mangueiras e jaqueiras já eram abundantes em Recife e Olinda, como descreve Tollenare ("a mangueira é a rainha das árvores nas cercanias do Recife"), mas é possível que novas variedades tenham sido introduzidas no jardim. A caneleira era também conhecida na região, apesar de pouco cultivada, conforme relata o mesmo cronista, alcançando-se sucesso no seu cultivo do jardim de Olinda, assim como do cravo e da "nogueira da Índia", nomeada pelo Diccionario de Botanica Brasileira ${ }^{5}$ como Aleurites baucurensis, espécie de Euphorbiaceae que, segundo a obra citada, foi cultivada pela primeira vez no Brasil no "extinto Jardim Botânico de Olinda", podendo também se tratar de Aleurites moluccana (L.) Willd, de cujo fruto extraem-se óleos, ou ainda outra espécie.

Dessas "árvores da Índia" cultivadas no jardim, parece que apenas umas poucas foram plantadas no terreno e se mantiveram por algum tempo, como a mangueira, o tamarindo, a caneleira e a tamareira, observadas no local por Gardner em 1837.

\footnotetext{
${ }^{3}$ Louis-François Tollenare nasceu em Nantes em 1780 e faleceu em 1834. Esteve no Brasil na condição de comerciante de algodão e relatou sua estadia em Recife e Olinda, de 1816 a 1817, em suas Notas Dominicais, das quais apenas as partes referentes a Pernambuco e Bahia foram traduzidas para 0 português e publicadas na Coleção Pernambucana, v. XVI, 1978. A obra completa, em dois volumes, Notes dominicales: prises pendant un voyage em Portugal et au Brésil em 1816, 1817 et 1818, foi reeditada pela Fundação Calouste Gulbenkian em 1972.

${ }^{4}$ George Gadner foi botânico, zoólogo e médico. Nasceu em 1812, em Glasgow e faleceu em 1849. Chegou ao Rio de Janeiro em 1836 e até 1841 viajou pela Bahia, Alagoas, Pernambuco, Ceará, Piauí e Maranhão, deixando relatos do que observava. Voltou para a Europa com um acervo grandioso de milhares de espécies vegetais, tornando-se diretor do Jardim Botânico, no Ceilão, onde faleceu. ${ }^{5}$ Diccionario de Botanica Brasileira, obra de 1873, disponível em http://pt.wikisource.org/wiki/P\%C3\%A1gina:Diccionario_de_botanica_brasileira.djvu/357
} 
Rodrigues et al. (2006) enfatizam o papel do horto no desenvolvimento agrícola de Pernambuco, destacando-se a aclimatação e distribuição da cana caiana (mais produtiva do que a cana crioula, cultivada na época) e do capim Angola.

Após a saída de Germain, uma série de diretores o sucedeu, com destaque Bernardo José Serpa Brandão (de 1822 a 1826), que veio a ser, em 1829, nomeado diretor do Jardim Botânico do Rio de Janeiro, exercendo esse cargo por 22 anos e sucedendo nesse cargo um outro pernambucano, Frei Leandro do Sacramento ${ }^{6}$.

Os últimos diretores do Horto Botânico (denominação da época) foram Joaquim Jerônimo Serpa ${ }^{7}$ e Bernardino José Serpa. O primeiro, médico merecedor de grande reconhecimento, lecionou Agricultura e Botânica, tendo como grande interesse as aplicações terapêuticas das plantas. O último diretor do jardim botânico, Bernadino José Serpa, foi segundo Rodrigues et al. (2006), nomeado em 1842, sendo a área posta a venda em 1844 e finalmente vendida para um particular em 1854, confirmando a ácida observação de Tollenare, no caso referente ao período da direção de Mr. Germain: "O jardim botânico de Olinda é ainda um exemplo do que se encontra tão amiúde em Portugal; quero dizer: concepções sábias e benfazejas abafadas por execuções infiéis e imprudentes".

Como propriedade particular (Sítio dos Manguinhos), a área assumiu a função de quintal, perdendo seus antigos usos, já decadente nos meados do século XIX. No século XX (1915) foi oficialmente reconhecido como "Velho Horto d'El Rey" e, a partir daí, uma série de bem intencionados decretos, leis e outras iniciativas vêm buscando garantir a sua preservação.

Em 1979, a FIDEM (Fundação de Desenvolvimento da Região Metropolitana do Recife) elaborou o Plano Diretor do Horto de Olinda, com vistas à implementação de um parque metropolitano. Nesse trabalho inclui-se o primeiro levantamento intensivo da vegetação existente, realizado pelo botânico pernambucano Dárdano de Andrade-Lima (ANDRADE-LIMA, 1979), no qual o pesquisador apresentou também suas sugestões para instalação do Horto de Olinda (definição legal das propriedades; cercamento de todo perímetro; exclusão das áreas já urbanizadas; elaboração o

\footnotetext{
${ }^{6}$ Bediaga (2007) registra os nomes desses dois pernambucanos na direção do Jardim Botânico do Rio de Janeiro, mas não relata que Bernardo José Serpa Brandão havia sido, anteriormente e por pouco tempo, diretor do jardim botânico de Olinda.

${ }^{7}$ Médico, Joaquim Jerônimo Serpa nasceu no Recife, em 1773. Estudou em Portugal, regressando a Pernambuco em 1808. Aderiu à Revolta Pernambucana de 1817, ficando, por esta razão, preso por quatro anos na Bahia. Libertado, voltou a Pernambuco, onde, em 1834, tornou-se professor de Botânica e, depois, diretor do Jardim Botânico de Olinda. Publicou alguns livros, entre os quais: "Tratado da Educação Psico-Moral dos Meninos" (1828) e "Compêndio de Botânica para Uso dos Alunos que se Quiserem Dedicar ao Estudo desta Ciência" (1835). Morreu em Pernambuco, em1842, deixando inacabado um "Compêndio de Agricultura Apropriada ao Clima desta Província". Disponível em www.peaz.com.br/biografias/joaquim_jeronimo_serpa.htm
} 
Horto D'el Rei de Olinda, Pernambuco...

zoneamento da área, em função das condições de relevo, construções existentes, cobertura vegetal e vias de acesso; estabelecimento de medidas corretivas para as paisagens; locação da área exata do antigo Jardim Botânico e introdução de maior número possível de espécies tropicais de valor econômico).

Mais recentemente, o Horto d'El Rey foi objeto de estudo de Lira (1999) e Figueiredo (2005), além de inspirar outros freqüentes trabalhos acadêmicos. Rodrigues et al. (2006) abordaram com precisão aspectos históricos de sua criação e alertaram para a necessidade de preservação e reestruturação da área, de forma a embelezar "ainda mais, a cidade considerada patrimônio da humanidade".

Como iniciativa da Prefeitura de Olinda, em 2008 foi contratado um trabalho de consultoria, com vistas a elaborar proposta de implantação e gestão da ARIE - Horto d'El Rey, consubstanciada em relatório (PICCHIONI, 2008) no âmbito do qual foram feitas as avaliações da cobertura vegetal que ensejaram o presente trabalho. $O$ relatório sugere a implantação do Parque Histórico e Natural do Horto D'El Rey, apresentando proposta de gestão, com modelo institucional e estratégias de parceria.

\section{Cobertura vegetal e aspectos gerais da paisagem}

A Área de Relevante Interesse Ecológico (ARIE) Horto d'El Rey caracteriza-se por elevada cobertura arbórea em sua maior parte, tanto nas encostas quanto nas partes baixas, com copas se tocando e se sobrepondo. Identificam-se, nesses locais, dois estratos verticais, sendo o inferior composto por arbustos e por árvores jovens ou dominadas, com altura até 3,0m, e o estrato superior com altura média de 6,0m. Árvores emergentes elevam-se acima do dossel, atingindo mais de $12 \mathrm{~m}$, posição que parece acentuada pela localização das árvores nas partes mais altas do terreno. Da ARIE também fazem parte algumas edificações, moradias dos atuais proprietários, incluindo jardins e outras áreas cultivadas.

Nas áreas sombreadas, o estrato subarbustivo é dominado pelo malvaisco (Piper marginatum, família Piperaceae), que recobre grande parte do solo, identificando-se aí expressiva regeneração natural das espécies arbóreas, notadamente do ingá (Inga sp.) e juazeiro (Ziziphus joazeiro). Nas margens de trilhas encontram-se touceiras de paquevira (Heliconia psittacorum, Heliconiaceae) e a presença de diferentes espécies da família Poaceae e Cyperaceae é mais freqüente em áreas onde o dossel se apresenta aberto.

Trepadeiras são comuns recobrindo as copas das árvores nas áreas com maior densidade arbórea, assim como a epífita Rhipsalis sp (Cactaceae), que forma belas cortinas, lançando-se em direção ao solo a partir dos altos galhos das cajazeiras (Spondias mombin), espécie cujas árvores são dominantes no dossel. 
Há sensíveis diferenças de estrutura da vegetação e de composição florística entre os ambientes, decorrentes da posição no terreno, proximidade aos corpos d'água ou linhas de drenagem e intensidade e tipo de pressão antrópica. Na área alagável, por exemplo, que funciona como bacia de captação da drenagem local, estabeleceu-se um conjunto quase uniforme de Elaeis guineensis, originados da germinação de sementes dispersas pela água.

Marcando a paisagem com a presença de exemplares antigos e frondosos, destacam-se as grandes mangueiras (Mangifera indica) de diferentes variedades, procuradas por coletores de frutos provenientes das comunidades vizinhas.

As áreas mais antropizadas apresentam cobertura arbórea esparsa, principalmente das moradias existentes e da estrada que permite fluxo de automóveis. Nesses locais dominam as espécies cultivadas, não se observando regeneração natural das espécies arbóreas, mas sim um estrato herbáceo constituído por ervas ruderais, típicas de ambientes com forte influência humana.

Nas encostas onde a ocupação humana exerce maior pressão, como nas proximidades de Amaro Branco, o componente arbóreo é representado apenas por exemplares esparsos, com destaque para a cajazeira, enquanto os estratos arbustivo e herbáceo são densos, constituídos por cultivos de bananeira (Musa sp, Musaceae), encontrando-se também Ricinus communis (mamona ou carrapateira, família Euphorbiaceae) e Solanum paniculatum (jurubeba, família Solanaceae), arbustos comuns em áreas antropizadas, e Montrichardia linifera (aninga, família Araceae) nas áreas mais úmidas. A presença de bananeiras é freqüente em outros locais da ARIE, principalmente nas encostas, nas suas porções intermediárias e inferiores. Foi encontrado um único exemplar de Lygodium sp, pteridófita escandente da família Schizaeceae, na margem de trilha em local antropizado.

Próximo às áreas urbanizadas do Bonsucesso, em local plano e desmatado anteriormente, observa-se um conjunto quase exclusivo de sabiá (Mimosa caesalpiniifolia), cujas árvores foram plantadas em espaçamento regular e de onde se explora a madeira que, dada as suas propriedades, é muito procurada para lenha.

A Tabela 1 apresenta a relação de árvores e arbustos lenhosos mais freqüentes, abundantes, em destaque pelo porte ou situação ou casualmente registrados durante os trajetos das trilhas realizadas na área. Também aí se relacionam as considerações sobre o hábito das espécies e ambientes onde foram observadas.

A riqueza em espécies arbóreas e arbustivas não foi elevada e foi composta em grande parte por espécies exóticas, típicas de quintais e de áreas urbanas 
Horto D'el Rei de Olinda, Pernambuco...

marginais, além de algumas poucas espécies características de estágios sucessionais iniciais da Mata Atlântica pernambucana. 
Tabela 1 - Espécies lenhosas, arbóreas e arbustivas, observadas no Horto d'El Rey, Olinda, Pernambuco, em 2008.

\begin{tabular}{|c|c|c|}
\hline Nome popular & Espécie & Família \\
\hline Araçá & Psidium guineense & Myrtaceae \\
\hline Araticum & Annona margravii & Annonaceae \\
\hline Aroeira & Schinus terebinthifolius & Anacardiaceae \\
\hline Azeitona roxa & Syzygium cuminii & Myrtaceae \\
\hline Cafezinho & Casearia sylvestris & Flacourtiaceae \\
\hline Cajazeira & Spondias mombin & Anacardiaceae \\
\hline Cajueiro & Anacardium occidentale & Anacardiaceae \\
\hline Caliandra & Calliandra sp & Fabaceae \\
\hline Calumbi & Mimosa pigra & Fabaceae \\
\hline Caneleira & Cinnamomum zeylanicum & Lauraceae \\
\hline Cássia grande & Cassia grandis & Fabaceae \\
\hline Coqueiro & Cocos nucifera & Arecaceae \\
\hline Dendezeiro & Elaies guineensis & Arecaceae \\
\hline Fruta-pão & Artocarpus altilis & Moraceae \\
\hline Imbaúba & Cecropia sp & Cecropiaceae \\
\hline Ingá & Inga bahiensis & Fabaceae \\
\hline Jaqueira & Artocarpus integrifolia & Moraceae \\
\hline Jenipapo & Genipa americana & Rubiaceae \\
\hline Juazeiro & Ziziphus joazeiro & Rhamnaceae \\
\hline Macaúba & Acrocomia intumescens & Arecaceae \\
\hline Mangueira & Mangifera indica & Anacardiaceae \\
\hline Mutamba & Guaxuma ulmifolia & Sterculiaceae \\
\hline Oiti & Licania tomentosa & Chrysobalanaceae \\
\hline Pau d'arco & Tabebuia sp & Bignoniaceae \\
\hline Pinheiro & Pinus sp & Pinaceae \\
\hline Pitangueira & Eugenia uniflora & Myrtaceae \\
\hline Pitomba & Talisia esculenta & Sapindaceae \\
\hline Sabiá & Mimosa caesalpiniifolia & Fabaceae \\
\hline
\end{tabular}

\section{Hábito e ambiente}

Arbusto raro, encontrado nas encostas

Árvore de médio porte, pouco freqüente, encontrada nas encostas.

Árvore de pequeno porte, pouco freqüente, encontrada nas encostas.

Árvore de médio porte, observada nas áreas mais baixas.Potencial invasor

Arvoreta do subosque, pouco freqüente.

Árvore de grande porte, dominante, ocorrente principalmente nas encostas.

Árvore de médio porte, pouco abundante.

Arvore de pequeno porte, pouco freqüente, nas áreas de encosta, cultivada.

Arvoreta de pequeno porte, esgalhada, irregularmente distribuída.

Observado apenas um indivíduo de pequeno porte, regenerante ou dominado.

Observado um único indivíduo de grande porte, no baixio, próximo à área de acúmulo de água.

Palmeiras de médio porte, distribuídas regularmente em toda área.

Palmeiras de médio porte, também presente na regeneração natural, com distribuição esparsa por toda área e em maciço na área alagável.

Árvore de médio porte, pouco freqüente.

Árvore com distribuição dispersa, em áreas abertas

Árvore de médio porte, às vezes frondosa, distribuída por toda área.

Árvore frondosa, de médio porte, regularmente distribuída na área.

Árvore de médio porte, com distribuição irregular, na meia encosta.

Árvore de pequeno porte, ocorrente na meia encosta e áreas baixas, profícua regeneração natural.

Palmeira de médio porte, distribuída irregularmente e formando "cordão" na média encosta.

Árvore frondosa de médio porte, muito freqüente, não raro com danos físicos, sinais de senilidade

ou problemas fitossanitários. Alguns exemplares têm porte majestoso. Ocorrem diferentes variedades (manguito, espada, roseira, Itamaracá, rosa)

Árvore de pequeno porte, pouco freqüente, na meia encosta e às margens das linhas d'água. Árvore de médio porte, com distribuição dispersa.

Árvore de médio a grande porte, encontrada na encosta, próximo a edificações.

Árvore de médio porte, aparentando má aclimatação ou problemas fitossanitários, encontradas proximas a moradias (cultivada).

Arbusto pouco freqüente.

Árvore de médio porte, não muito freqüente, ocorrendo principalmente nas áreas baixas mas não inundáveis.

Arvoreta esgalhada, formando maciço, explorada para estacas e lenha.

REVSBAU, Piracicaba - SP, v.4, n.2, p.62-81, 2009 
Horto D'el Rei de Olinda, Pernambuco...

A dispersão de propágulos por morcegos (quireptocoria), que parece ser a síndrome de dispersão mais importante em áreas urbanas, alimentada pela preferência do cultivo de fruteiras em quintais, foi provavelmente responsável pela atual composição florística da área, assim como a dispersão pela água de drenagem (hidrocoria) contribuiu para determinar a distribuição espacial de algumas espécies.

A grande proporção de espécies com frutos suculentos apreciados pela fauna e pelas pessoas é um aspecto importante a ser considerado nas estratégias para sua conservação. A estratificação da vegetação e a multiplicidade de nichos ecológicos representam outros atributos importantes a serem conservados e amplificados.

De uma forma geral, a área do Horto d'El Rey destaca-se pelo valor de sua cobertura arbórea e quantidade de fitomassa estocada, constituindo-se em importante fator de amenização microclimática, além de desempenhar papel protetor do relevo e do solo. O efeito da vegetação na redução dos extremos de temperatura é notório aos visitantes, assim como a amortização dos ruídos urbanos, proporcionando sensação de frescor, tranqüilidade e bem-estar quando se está em seu interior.

\section{Evolução da paisagem e história recente de uso}

Comparando-se a paisagem atual à descrita nos documentos de 1977 e 1979 (FIDEM, 1977; 1979 e ANDRADE-LIMA,1979), elaborados com vistas a diagnosticar aspectos ambientais do Horto d'El Rey para definir estratégias para a sua conservação, verifica-se que, já nessa época, o recobrimento arbóreo era composto predominantemente por fruteiras, encontradas nas vertentes, nas áreas de tabuleiros e em alguns locais nos vales. É interessante registrar que parece não ter se evidenciado, há trinta anos, a dominância das cajazeiras (Spondias monbin), embora Andrade-Lima (1979) aponte a sua ocorrência.

Há referências, na fonte citada, à cobertura de vegetação rasteira, higrófila, no vale, e à presença de campo limpo nas áreas consideradas sem recobrimento vegetal, identificando-se também áreas de agricultura de subsistência, não observadas atualmente. Esses aspectos não se fazem presentes hoje tanto por provavelmente terem dado lugar a um processo sucessional que promoveu o desenvolvimento de espécies arbustivas e arbóreas, como também porque o levantamento realizado há cerca de 30 anos abrangeu uma área maior, já em grande parte ocupada por edificações, principalmente na porção noroeste e na gleba denominada Quintas de Rei.

Embora não tendo sido possível se resgatar a imagem e o zoneamento que serviram de base para as descrições de Andrade-Lima, as descrições permitem 
deduzir que a paisagem correspondia em grande parte ao que se encontra hoje no Horto d'El Rey, podendo-se intuir que houve uma redução na área total mas, ao mesmo tempo, aumento do porte, da densidade arbórea e da regeneração natural das espécies arbóreas.

O estudo de Andrade-Lima (1979) apresenta extensa relação florística, mas é preciso atentar que a grande maioria das espécies citadas se constitui em ervas ou subarbustos ruderais, invasores, heliófitos e amplamente distribuídos em áreas degradadas como terrenos abandonados e margens de estrada. Sendo assim, não há porque supor que nos últimos trinta anos tenha havido redução na riqueza e na diversidade de espécies ou comprometimentos das funções ambientais da área, mas sim uma diminuição na diversidade de ambientes presentes.

Não há registros nem evidências de antigos plantios de espécies arbóreas, nativas ou introduzidas, formando arboretos que tenham servido ao estudo da flora, não justificando o nome nem as expectativas de uso como "jardim botânico". Após o período servindo como espaço para aclimatação, produção, distribuição de mudas e cultivo de plantas medicinais, seguidos por mais de 150 anos como propriedade particular, a área sofreu o manejo dado aos sítios, privilegiando o plantio ou a simples manutenção de fruteiras tradicionalmente apreciadas. Nos últimos trinta anos, estabeleceu-se uma vegetação secundária espontânea, formada por espécies comuns em sítios ou áreas marginais dos centros urbanos de Olinda e Recife.

A área passou por um processo de "naturalização" do qual, não havendo fragmentos florestais nas proximidades, resultou uma vegetação secundária pobre em espécies, dominada por algumas poucas espécies de fácil adaptação e crescimento rápido, cujos propágulos originaram-se de quintais próximos, além de parte ser introduzida como espécies úteis aos proprietários e moradores das vizinhanças.

Os usos atuais promovem impactos ambientais de fracos a medianos: nas visitas realizadas foi observada a presença de coletores de frutas e de usuários de drogas ilícitas, havendo várias possibilidades de entrada no local de pessoas não autorizadas. Essa entrada, embora não permitida pelos atuais proprietários, é de certa forma tolerada, já que não há condições efetivas de coibi-la.

Foram vistos alguns coqueiros cortados para extração posterior do estipe, para uso em artesanato, e cascas de cajazeiras também são coletadas para a confecção de pequenas talhas comercializadas no Alto da Sé, aparentemente sem maiores danos às árvores. Construções próximas fazem uso da areia do local e, além da exploração de sabiá e coqueiro, não parece haver cortes freqüentes de árvores. As maiores ameaças vêm da das ocupações periféricas, que reduzem, dia-a-dia, a área verde do Horto d'El Rey. 
Horto D'el Rei de Olinda, Pernambuco...

\section{Potencialidades como área verde (pública?)}

O Horto d'El Rey tem hoje, como principais atributos, a sua situação geográfica, constituindo-se em área verde com densa cobertura arbórea no Centro Histórico de Olinda, e uma história que, se bem já em parte resgatada por alguns pesquisadores, precisa ser melhor estudada e conhecida pela população.

Se a condição fisiográfica, por um lado, dificulta o acesso das pessoas, por outro permite um ângulo de visão inédito, podendo-se apreciar, do Alto da Sé, as copas das árvores que descem as encostas em direção ao oeste.

Projetos anteriores para o Horto d'El Rey, geralmente apenas enunciados e não inteiramente formulados, pretendendo torná-lo um "jardim botânico" ou um "parque metropolitano", ou ainda a sua situação de Área de Relevante Interesse Ecológico (ARIE), esbarram em questões ainda mais profundas do que a pouca exeqüibilidade. Para se constituir em um jardim botânico, o Horto d'El Rey deveria contar com "coleções especiais da flora nativa" em instalações adequadas, herbário e quadro técnico especializado adequado, entre outras condições, conforme a Resolução CONAMA 339, de 25/09/2003 (CONAMA, 2003). Além disso, e igualmente fundamental, deveria estar associado à instituição com tradição e meios para conduzir pesquisas botânicas relevantes, mantendo infra-estrutura, corpo técnico-científico, intercâmbios e projetos de pesquisa compatíveis aos objetivos.

Como parque metropolitano, seriam grandes os impactos de vizinhança haja vista a proximidade das comunidades aos limites da área, além de severas as restrições de acesso ao local e certamente intensos os impactos ambientais no seu interior, posto que exigiria atrações de recreação e lazer incompatíveis com os recursos e limitações físicas existentes.

Já a sua qualificação como ARIE é, neste como em vários outros casos, a alternativa que o Poder Público recorre para conferir alguma proteção e frear usos mais impactantes por parte dos proprietários, embora haja discordância entre as características da área e a definição dessa categoria de Unidade de Conservação: Segundo a Lei 9.985, de 18 de julho de 2000, que institui o Sistema Nacional de Unidades de Conservação (BRASIL, 2000), “Área de Relevante Interesse Ecológico é uma área com pouca ou nenhuma ocupação humana, com características naturais extraordinárias ou que abriga exemplares raros da biota regional, e tem como objetivo manter os ecossistemas naturais de importância regional ou local e regular o uso admissível dessas áreas, de modo a compatibilizá-lo com os objetivos de conservação da natureza".

É importante lembrar que essa discordância é quase uma constante quando se avalia a adequação das categorias de unidades de conservação previstas no Sistema 
Nacional de Unidades de Conservação, claramente preocupado com a conservação de ecossistemas naturais relevantes ou ameaçados, aos espaços livres urbanos, geralmente resultados de sucessivas intervenções antrópicas e onde as questões socioculturais e urbanoambientais sobrepõem-se, não raro, aos valores ecológicos.

Para essas situações urbanas, precisa-se contar com um Sistema Municipal de Áreas Verdes, capaz de identificar e valorizar diferenças de atributos entre as áreas e, consequentemente, estabelecer usos permitidos, incentivados e proibidos.

Intervenções futuras no Horto d'El Rey devem respeitar a cobertura vegetal espontânea, inclusive o estrato subarbustivo, importante na conservação dos solos, notadamente nas partes com declive mais acentuado. O uso público mais intensivo deverá ser restrito aos locais já fortemente modificados, nas proximidades das edificações, haja vista as condições de acesso e limitações do relevo.

Áreas planas próximas à entrada do Bonsucesso precisam ser objeto de restauração ambiental, qualificando-as para o lazer contemplativo e para a condução de práticas educativas, nas quais se priorizem as ações de inclusão social, saúde, educação ambiental e cidadania, voltadas principalmente às comunidades do entorno. Já na parte que tem acesso pelo Alto da Sé, atração turística importante, deve-se valorizar as estratégias de informação sobre importância do local na introdução de espécies exóticas que hoje integram a paisagem, a cultura e a economia regionais.

Nas áreas de uso intensivo pode ser proposto o corte de árvores de espécies introduzidas e não adequadas ao ambiente, como os poucos exemplares de Pinus sp. existentes, assim como a remoção de arbustos invasores ou cultivados, enriquecendoas, por outro lado, com espécies nativas de grande potencial paisagístico, citadas por Andrade-Lima (1979) como existentes no local: angelim (Andira nitida), embiriba (Eschweilera ovata), japaranduba ou jeniparana (Gustavia augusta), jacarandá-branco (Swartzia pickelli) e pau-ferro (Caesalpinia ferrea).

Já nas áreas mais primitivas, de difícil acesso, a visitação deve ser restrita a trilhas definidas, podendo-se sugerir a instalação de passarelas estreitas, confeccionadas com madeira certificada, com percursos limitados, de onde seja possível se vislumbrar aspectos importantes da paisagem olindense, como o Farol de Olinda, ajudando a entender a importância do relevo na escolha do local para fundação da antiga Vila de Olinda.

A garantia de segurança é uma condição primordial para qualquer iniciativa de recepção de visitantes, serviço que deverá incluir pessoas das comunidades vizinhas, devidamente treinadas, remuneradas e aparelhadas. A presença de coletores de frutas poderá ser permitida, obedecendo a regulamento especialmente elaborado, 
Horto D'el Rei de Olinda, Pernambuco...

enquanto as demais atividades deverão ser coibidas, principalmente quando se constituem em infração ou causem constrangimento à comunidade.

Esses usos, embora possam ser compatíveis com a propriedade particular, dificilmente alcançariam sustentabilidade financeira se promovidos pelos proprietários. Dado o caráter coletivo dos valores histórico e ambientais associados ao Horto d'El Rey, sua constituição como área verde pública, com gestão especialmente voltada às atividades educativas e à conservação da cobertura vegetal e fauna lá existentes, deve ser responsabilidade do Poder Público.

\section{CONCLUSÕES}

Como jardim botânico, o Horto d'El Rey passou por três fases em cerca de 40 anos (início do século XIX até 1842): em um momento que antecedeu a sua oficalização, foi área para estudos e experimentação botânica, capitaneados por Arruda Câmara e padre João Ribeiro; em seguida, servindo aos interesses da Coroa, foi um entreposto de produção, aclimatação e distribuição de mudas de espécies vegetais economicamente valiosas e, por fim, parece ter sido campo de ensino e pesquisa de plantas medicinais.

A vegetação hoje existente não apresenta aspectos notáveis a serem observados quanto à diversidade, riqueza e raridade das espécies presentes, refletindo uma história de uso de uma área vulnerável às intervenções humanas, planejadas ou não, no coração de um centro urbano com cinco séculos de ocupação, altamente insularizado e sujeito a pressões em todo o seu perímetro. Por outro lado, destacam-se o porte das árvores e a cobertura que proporcionam, sendo esses valores a serem respeitados e amplificados, caso se pretenda implementar um projeto de uso público para a área.

O futuro da área depende inteiramente das decisões a serem tomadas e das conseqüentes ações, "fiéis e prudentes", de forma a se poder comemorar dignamente, em 2011, o bicentenário do Horto d’El Rey.

\section{REFERÊNCIAS}

ANDRADE-LIMA, D. A cobertura vegetal do Horto de Olinda. Recife: Relatório de trabalho, 1978.

BRASIL. Lei 9.985, de 18 de julho de 2000. Regulamenta o art. 225, § 1º, incisos I, II, III e VII da Constituição Federal, institui o Sistema Nacional de Unidades de Conservação da natureza e dá outras providências. In: MEDUAR, O. (org.) Constituição federal, coletânea de legislação de direito ambiental. São Paulo: editora revista dos Tribunais, 2003. 
BEDIAGA, B.. Conciliar o útil ao agradável e fazer ciência: Jardim Botânico do Rio de Janeiro - 1808 a 1860. História, Ciência e Saúde, v. 14, n. 4, p. 1131-1157. 2007.

CONAMA Resolução № 339 de 25/09/2003. Dispõe sobre a criação, normatização e o funcionamento dos jardins botânicos, e dá outras providências. Disponível em http://www.mma.gov.br/port/conama/legiabre.cfm?codlegi=377

FIDEM Região metropolitana do Recife: Restrições físicas do Horto de Olinda. Recife: Fundação de Desenvolvimento da Região Metropolitana do Recife, 1977.

FIDEM Plano Diretor do Horto de Olinda: Aspectos históricos - pesquisa bibliográfica. Recife: Fundação de Desenvolvimento da Região Metropolitana do Recife, 1979.

FIGUEIREDO, F. F. Revitalização Paisagística do Horto Del Rey, Olinda IPE. 2005. (Trabalho de Conclusão de Curso de Arquitetura e Urbanismo, Faculdade Esuda, 2005)

FREYRE, G. Olinda: $2^{\circ}$ guia prático, histórico e sentimental da cidade brasileira. Rio de Janeiro: José Olympio. 1939.

LIRA, N. S. A importância do Jardim Botânico de Olinda para a Província de Pernambuco no Século XIX. Olinda, 1999. (Monografia do Curso de Especialização "Olinda no Contexto Mundial", FUNESO, 1999)

MELLO, J. A. G. Manuel Arruda da Câmara: Obras reunidas c.1752-1811. Recife: FCR, 1982.

MOULIN, D.; MAULE, A. F.; ANDRADE-LIMA, D.; RAHN, K.; PEDERSEN, T. M. 0 herbário de Georg Marggraf. Rio de Janeiro: Fundação Nacional Pró-Memória; Recife: Fundação do Patrimônio Histórico e Artístico de Pernambuco. 1986.

PICCCHIONI, S. A. Parque histórico natural Horto d'El rey: projeto de implantação e gestão do Horto d'El Rey: relatório técnico final. Olinda, 2008. (Circulação restrita, não publicado).

ROCHA, Y.; CAVALHEIRO, F. Aspectos históricos do Jardim Botânico de São Paulo. Revista Brasileira de Botânica, São Paulo, v .24, n.4 (suplemento), dez. 2001, p.577586.

RODRIGUES, J. ; DUTRA, M. ; ALBUQUERQUE, P. ; DIAS, S. ; ALMEIDA, A. V.. Aspectos histórico-ecológicos do Horto d'El Rey de Olinda, Pernambuco. Mneme Revista de Humanidades, Caicó, v. 7.n. 19, dez. 2005/jan. 2006. p. 388-413. Disponível em http://www.seol.com.br

SILVA, M. A. . Um jardim plantado nos trópicos: Nassau, 400 anos, e uma experiência paisagística pioneira na América. In: Encontro Nacional de Ensino de Paisagismo em Escolas de Arquitetura e Urbanismo, 7, 2004, Belo Horizonte. Anais... Disponível em:. http://www.usp.br/fau/depprojeto/gdpa/paisagens/inicio.html 
Horto D'el Rei de Olinda, Pernambuco...

TOLLENARE, L. F. Notas dominicais. Coleção Pernambucana, v. 16. Recife, 1978. 